\title{
Structural and functional analysis of the centrifugal pump development as a technical system
}

\author{
Olga Dubrovskaya ${ }^{1, *}$, Ivan Inzhutov ${ }^{1}$, Anastasya Bobrik ${ }^{1}$, and Aleksey Klimov ${ }^{1}$ \\ ${ }^{1}$ Siberian Federal University, School of Engineering and Construction, 82 Prospect Svobodny, Kras- \\ noyarsk 660041, Russia
}

\begin{abstract}
Pumping equipment is one of the main systems of water supply and sewerage, where centrifugal pumps are mostly used due to the simple design and the optimal interval of the parameters of flow and pressure. The paper considers the development of a centrifugal pump from the point of view of system analysis, since this approach considers any technical object as a complex of interacting elements having the properties that are not reduced to the properties of individual elements designed to perform certain useful functions. The aim of the paper is to find patterns of development of the centrifugal pump as a technical system to predict its further evolution. Domestic and foreign patent fund of Class F 04 D in the amount of 724 units was used as the main source. In the paper, the device of the centrifugal pump as a technical system is divided into the following main structural subsystems: impeller blades, impeller disks; housing; pressure pipe and suction pipe. Each of these elements has its main useful function and a number of auxiliaries, which are discussed in detail. It is established that an increase in the degree of control of the centrifugal pump can be achieved by dynamization of transmission, specifically, the regulation of the revolutions transmitted from the engine to the impeller mechanically, with the help of fluid coupling and frequency converters.
\end{abstract}

\section{Introduction}

The invention of the centrifugal pump goes back to the XVII century. However, due to the lack of high-speed engines, these devices could not compete with piston ones, being inferior to them in all operational parameters. Only in the late nineteenth century, with the advent of high-speed thermal, and then electric motors, centrifugal pumps started to be widely used. But the perspective of these devices was assessed by another great mathematician, Leonard Euler, who in 1754, studying the theory of centrifugal machines, developed the basis of the modern mathematical apparatus describing their work [1].

The classical form of the impeller of a radial type inherent in modern centrifugal pumps was used in 1818 in Boston in the so-called "Massachusetts pump". At that time, it concerned a spiral pump with a semi-open impeller and straight radial blades. In 1846, English engineer G. Andreas proved that the curved blades provide the best effect of injection than

\footnotetext{
*Corresponding author: dubrovskayaolga@mail.ru
} 
direct ones. Based on his experience, in 1850, industrialist J. Gwynne brought to the UK market the first patented double spiral pump with closed impeller and curved blades, which received the most widespread use.

In 1925, German Professor C. Pfleiderer found a relationship between the finite number of blades and the hydraulic characteristics of the pump that gave an impetus to its further improvement.

\section{Methods and materials}

Let us consider further development of the centrifugal pump from the point of view of system analysis. This approach consists in the consideration of any technical object as a set of orderly interacting elements with properties not reducible to the properties of individual elements designed to perform certain useful functions.

The structure of any technical system is a collection of elements (subsystems) and the relationships between them, which are determined by the physical principle of the implementation of the desired useful functions. Relationships between subsystems can be mechanical, hydraulic, electrical, and informational, in other words - substance and field relationships. The structure of the technical system remains unchanged during operation, and the main requirement to it is minimal energy loss and unambiguous actions.

In technical systems, there is always a hierarchy of functions. Each technical system performs the main useful function for which it exists. For the centrifugal pump, this function is to give energy to the pumping environment. There is also a number of auxiliary functions lower in hierarchy, which are designed to provide the most effective performance of the main useful function.

\section{Results}

Studies have shown [3] that any viable technical system contains the following interrelated elements: energy source, the engine, transmission, operating body, and the governance body (Fig. 1). If you do not have any of these parts, it is the function of people or the environment.

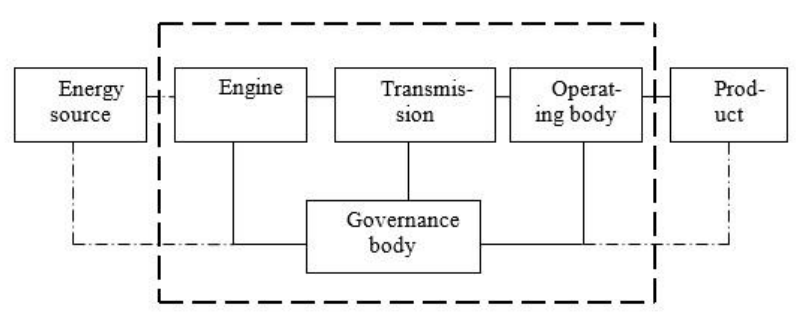

Fig. 1. Set of elements of the technical system

If you divide the centrifugal pump into these elements, it is obvious that the operating body would be the impeller blades, because they give the pumped environment the energy of further movement. Wherein, the said environment (pumped fluid) is a product which processes the operating body. Real working function is the impact on the subject or substance. Therefore, the operating body is the function carrier in its pure form, i.e. the only functionally useful part of the technical system. All the other parts are auxiliaries. 
The function of the transmission is performed by multiple subsystems. They are: the motor shaft, the shaft of the impeller, and the impeller discs to transmit rotational energy directly to the operating body - the impeller blades.

The energy source is an electric current, and the motor performs its direct function as a converter of energy from one form to another.

The governance body can be automatic or it can be a person controlling the modes of operation of the pump. For the technical system to be controlled, it is necessary that at least one part of it was manageable. To be controlled means to change properties (parameters) as necessary for the one who governs.

A centrifugal pump as a technical system can be divided into the following main structural subsystems: the impeller blades, the discs of the impeller, the body, the discharge nozzle, and the suction nozzle. Each of these elements has its main useful function and a number of auxiliaries. Let us consider their development in details.

\subsection{The impeller blades.}

These are the operating bodies of the technical system; therefore, they perform its main useful function.

Direct blades of the first centrifugal pumps.

Curved blades with a single operating plane.

Curved blades with multiple operating planes

The authors of technical solutions argue that if the impeller blades have not only one operating plane but multiple consistent planes, this leads to a significant improvement of the main useful function.

The blades crushing

One can get some concerted operating planes by the blades crushing. Instead of a group of similar blades, the authors of these technical solutions propose to apply the design of the impeller, which simultaneously accommodates blades of different curvature and different lengths. Coordinated work of blades of different configurations allows not only to increase the main useful function of the pump, but also to protect its work from the parasitic resonance phenomena, because the blades of a different configuration have different natural frequency.

Blades with an automatically variable operating area

According to the technical solution, spring-loaded blades are able to change their active radius depending on the speed of rotation of the impeller, which allows automatic regulation of pressure and flow.

The elastic blades of the impeller of the open type, changing its bending radius

The change in the curvature of the blades is done by changing the pressure of the working fluid from an external source in the zone of hinge of the blades to the shaft. It allows forcibly obtaining an optimum radius of curvature for different rotation speeds.

The bending radius of the blades can be changed depending on the temperature of the fluid. A low-boiling gas located in the inner cavities of the blades can act as a working body influencing the hinging of the blades. Such technical solutions are primarily designed for centrifugal pumps serving to pump a coolant, e.g. coolant in nuclear power plants.

The change in the volume of the geometry of the impeller blades, in which the blades are made from material with shape memory effect, allow changing not only the radius of curvature of the blades, but the shape of their surface both in automatic and forced modes

In the first case, the change of the volumetric geometry of the blades comes from the change of temperature of the pumped medium, in the second - by means of the forced heating. 
An ideal technical solution is the one in which the pumped fluid itself would set the optimal parameters of the volumetric geometry of the impeller blades.

In addition to performing the main useful function, the impeller blades are able to perform auxiliary functions, namely: protection from parasitic resonance phenomena, compensation of the axial forces acting on the impeller and reducing the possibility of cavitation breakdown. This is achieved by making different kinds of extra holes and ejector cracks.

\subsection{Discs of the impeller.}

The main useful function is the creation of operating volume together with the blades.

The impeller consisting only of blades, having neither driving, nor driven disks.

The accumulation of scientific and practical knowledge has shown that the blades shall be rigidly fixed between the two discs, because the impeller speed has increased; it required more pressure and flow rate of the pumped medium, and in the absence of disks, the flow of fluid randomly scattered inside the body, causing strong vibration and noise. The use of the impeller discs has created flow laminarity.

The technical solution is noteworthy, where a diaphragm capable of increasing the displacement between the disks in combination with the blades, due to the axial movement of the diaphragm, which plays the role of a single disk.

Driving and driven discs can be made of elastic material which will automatically change the displacement depending on the pressure of the fluid.

The forecasted technical solution in which the disks are made of the material with shape memory effect and under certain conditions (cavitation, axial force), will have holes or protrusions (balances) that will offset or completely eliminate these phenomena.

Changes in the discs can occur both automatically and forcibly.

In addition to performing the main useful function, the disks of the impeller perform auxiliary functions. Namely: protection from cavitation through the holes in the disks, as well as elimination of axial forces with the help of active, passive balances and balance weights.

\subsection{The discharge nozzle}

The main useful function - reception and canalization of the fluid with high energy.

The discharge nozzle of a constant diameter.

The discharge nozzle of a modified diameter (diffuser).

The discharge nozzle of elastic material, capable of changing the diameter of the orifice.

Auxiliary functions:

- Throttling by the isolation valves.

- Throttling by changing the diameter of the pipe.

- The removal of pressure with the purpose of unloading from axial forces.

- The removal of a portion of the liquid to prevent cavitation breakdown.

\subsection{The suction nozzle}

The main useful function of the suction nozzle

- feeding the pumped medium. There is also an auxiliary function - cavitation prevention.

The suction nozzle of a constant diameter.

The suction nozzle of variable diameter, which is made of elastic material and is able to reduce the conditions of cavitation breakdown. 


\subsection{Body. The main useful function of the body is that it directs the fluid to the discharge nozzle. Its subsidiary function is the organization in space of all elements of the pump in a rigid structure.}

\section{Classical body}

A spiral - like pump body for the implementation of a smooth withdrawal of fluid from the impeller to the forcing pipe, as well as for the permanent speed reduction of the fluid motion with the aim of increasing the pressure. The living section of the spiral chamber to the pump outlet increases.

The use of the barrier in spiral body, due to which radial forces influencing the impeller are balanced.

The body with the possibility of changing working volume of the pump by means of a flexible diaphragm.

\section{Discussion}

The analysis above shows that the development of the pump as a technical system is aimed primarily at improving its controllability. It is performed by almost all subsystems of the pump from the blades to the body. Moreover, it is clear that the more important the function of a subsystem, the more it affects the main useful function of the pump, the more technical solutions aimed to manage this subsystem. One of the mechanisms of such control is the dynamic modification of technical systems [2].

Long-term studies on the analysis of the development of technical systems in various fields of technology revealed some common patterns. In particular, it concerns the mechanism of dynamic modification. According to the general definition of dynamic modification, it is an adaptation of the system to a changing environment interacting with it.

The adaption itself, in turn, consists of three stages: unstable, passive and active adaptation at different hierarchical levels of organization of the system. This adaptation occurs in a specific sequence. Therefore, it can be identified and used in the planned and forecast development of the technical systems undergoing adaptation.

Research has proved that systems with rigid connections tend to become dynamic to improve their effectiveness, i.e. they pass to a more flexible, rapidly changing structure and operation, adapting to changes in the external environment. Hard internal relations do not allow changing the mode of operation under changing external conditions. Because of this, the systems are vulnerable, often are damaged, and short-lived.

For mechanical systems which include a centrifugal pump, the dynamic modification process begins with the transition from stationary to moving parts. Hard link or design looks as if "broken," and in this place, the joint is introduced. The rigid elements are replaced by more flexible, for example by hydro- and air-inflated structures, vibration is used, periodic change of form, etc. For subsequent stages, the dynamic modification is characterized by the use of physical and chemical effects and phenomena, the introduction of feedback, the replacement of subsystems by perfect (smart) substances, "intellectualization" of the whole technical system.

The basis of the dynamic modification process is fundamental principles of the organization of natural processes. For example, if any system in equilibrium is influenced from outside, changing any of the conditions (temperature, pressure, concentration, etc.), the equilibrium in the system shifts in such a way as to reduce this change.

Typical chain dynamic modification of technical systems looks as follows: single joint many joints - flexible substance - liquid - gas - field [2]. Moreover, the technical system does not necessarily pass through all the stages of dynamization and not all systems reach 
in its development the end of the chain. It is important that the process of dynamization increases controllability of all subsystems and technical systems in general.

As an illustration, the dynamic modification of the transmission of the centrifugal pump can be given, where the rotational speed of the impeller first is regulated mechanically by the gearbox, then hydraulically - by hydraulic couplings, and finally, with the help of frequency converters, i.e. electric field.

The general scheme of the rational algorithm of dynamic modification [3] is presented in Figure 2.

\begin{tabular}{|c|c|c|c|c|}
\hline \multicolumn{5}{|c|}{$\begin{array}{l}\text { DEPLETION OF RESOURCES ON THE LEVEL ABOVE THE SYSTEM } \\
\text { Combination of systems by movable flexible links }\end{array}$} \\
\hline \multicolumn{3}{|c|}{ Two rigid systems with movable links } & \multicolumn{2}{|c|}{ Many rigid systems with movable links } \\
\hline \multicolumn{5}{|c|}{$\begin{array}{l}\text { DEPLETION OF RESOURCES ON THE SYSTEM LEVEL } \\
\text { Division of the system into parts and by means of movable flexible links }\end{array}$} \\
\hline Rigid systems & $\begin{array}{l}\text { Two-pa } \\
\text { tem with } \\
\text { or movabl }\end{array}$ & $\begin{array}{l}\text { st sys- } \\
\text { flexible } \\
\text { links }\end{array}$ & $\begin{array}{l}\text { Many-part sys- } \\
\text { tem with movable } \\
\text { flexible parts }\end{array}$ & $\begin{array}{l}\text { Many-part sys- } \\
\text { tem with contact } \\
\text { links }\end{array}$ \\
\hline \multicolumn{2}{|c|}{ Flexible elastic system } & \multicolumn{2}{|c|}{$\begin{array}{l}\text { Two-part system with dif- } \\
\text { ferent flexibility }\end{array}$} & $\begin{array}{l}\text { System of many } \\
\text { parts with variable } \\
\text { flexibility }\end{array}$ \\
\hline \multicolumn{2}{|c|}{ System with fluid elements } & \multicolumn{2}{|c|}{ Two-fluid system } & $\begin{array}{l}\text { System of varia- } \\
\text { ble fluids }\end{array}$ \\
\hline \multicolumn{2}{|c|}{ System with gas elements } & \multicolumn{2}{|c|}{ Two-gas system } & $\begin{array}{l}\text { System of varia- } \\
\text { ble gases }\end{array}$ \\
\hline \multicolumn{2}{|c|}{ System with the field use } & \multicolumn{2}{|c|}{$\begin{array}{l}\text { System with the use of } \\
\text { two variable fields }\end{array}$} & $\begin{array}{l}\text { System with the } \\
\text { use of many fields }\end{array}$ \\
\hline \multicolumn{5}{|c|}{ COMBINATION OF DIFFERENT TYPES OF DINAMIZATION } \\
\hline \multicolumn{5}{|c|}{$\begin{array}{l}\text { DEPLETION OF RESOURCES ON THE LEVEL OF SUBSTANCE } \\
\text { Combination of variable substances and transition to physical structures }\end{array}$} \\
\hline \multicolumn{2}{|c|}{$\begin{array}{l}\text { Rigid uniform mono- } \\
\text { substance }\end{array}$} & \multicolumn{2}{|c|}{$\begin{array}{l}\text { System of two different } \\
\text { mono-substances }\end{array}$} & $\begin{array}{l}\text { System of many } \\
\text { uniform mono- } \\
\text { substances }\end{array}$ \\
\hline
\end{tabular}

Fig. 2. The rational algorithm of dynamization of technical systems

In addition to the above examples, we can highlight some more technical solutions aimed at the dynamization of the subsystems of the centrifugal pump.

The impeller blades.

Hard blades - spring loaded (hinge) - elastic (reversible) - regulated (an alloy with shape memory).

According to the technical solution, each blade at the outlet in the area close to the discs is provided with slots made with the length equal to the width of interblade channel at the entrance. When solid particles occur between the blade and the body, the end of the blade is deformed due to the presence of the slots. They transmit solid inclusion in the interblade space and return to the starting position. This design of the blades is intended to reduce hydro-abrasive wear of the blades and is applicable to the pumped medium, which contains large inclusions.

The blades can be fixed to the impeller by bearings having axes and are provided by means of their rotation and fixation. Technical solution allows reducing the influence of axial forces and increasing the service life of the bearings.

The blades are made of elastic material and freely rotate on the axles connecting the driving and driven disks containing the ledges to the inside of the wheel, restricting the rotation of the blades. This design provides increased efficiency of the pump. Such a pump is called reversible due to the possibility of rotation of the blades in both directions.

The last step of dynamization is a technical solution in which the blades are made of alloy with shape memory effect, i.e. from a material with predetermined properties. 
Thus, an aggregate scheme of development of the impeller blades is a chain of the following technical solutions: straight blades - curved blades in one plane - curved blades in several planes - crushing of blades - ejector cracks in the blades - movable ends of the blades to change the active radius - blades made of elastic material - change of the volumetric geometry of the blades.

The specified sequence of technical solutions corresponds to the algorithm for the dynamic modification, which, in turn, does not contradict the general scheme of development of technical systems, which describes two opposite processes taking place in the development of any of them. They are the deployment - the complexity with the emergence of new subsystems increasing the main useful function and folding - the process of combining several functions by one subsystem, with a simplified design without reducing the main useful function.

The disks of the impeller have the following stages of modification: hard discs - disc diaphragm - disks of elastic material.

The impeller may be provided with a diaphragm, which serves as an intermediate disk and can move in the axial direction. This intermediate disk is provided with a drive and is connected by communication elements. When there is a need to change the pump flow, a signal from the user is supplied to the actuator, which moves the diaphragm in the axial direction.

The driving and driven discs can be made of elastic material and reinforced with plates. When armature in the form of plates of a more rigid material than the discs is embedded in disks, it is possible to adjust the degree of deformation of the disks and to regulate their rigidity. The driving and driven discs with the blades located between them form the interblade channels of the adjustable meridional section.

In the process of dynamization, the discharge nozzle goes through the following stages: discharge nozzle of a constant diameter - the discharge nozzle of a variable diameter. For example, it can be installed in the position of a different flow section at the exit from the spiral outlet due to the availability of the pivoted "language" depending on discharge pressure . This solution provides maximum efficiency in the case of feed reduction caused by increasing the external discharge resistance.

The suction nozzle has practically an analogous structure with the discharge one: the suction nozzle of a constant diameter - the suction nozzle with a variable diameter, made of elastic material and provided with the drive mechanism with the working body. This allows changing the area of the meridional cross section of the inlet pipe and reducing the threat of cavitation breakdown. It should be noted that cavitation can perform a useful function disinfection of the water pumped, i.e. the destruction of any organic matter, including harmful microorganisms [4-6]. But it is technically difficult to achieve controlled cavitation inside the pump body, so the cavitation is brought beyond the boundaries of the discharge nozzle into the pipeline. Cavitation is created there by a special nozzle on the discharge nozzle.

The body dynamization is performed as follows: the hard case - the case changing the working volume - the housing, eliminating axial forces - the case with a form-generating insert.

The pump working volume can be adjusted by a diaphragm of a porous material with the possibility of radial movement of the latter. Fluid of high pressure is fed or pumped to the diaphragm through the valve, and thereby the working volume of the pump chamber is regulated. This technical solution increases the efficiency of the pump.

For automatic unloading of the impeller from the axial force, the following technical solution is suggested. In the body, a movable element is mounted, which is made in the form of an annular membrane, fixed at the edges, and the annular chamber communicates with the discharge line through the channel in which a reducing valve is installed. The device for 
balancing the axial forces is supplied by the axial force sensor associated with reducing valve. With the appearance of axial forces, the sensor sends a signal and, gas is provided through the reducing valve, causing a deflection of the membrane. The gap between the membrane and the end of the impeller gradually decreases along with axial forces reduction. The process continues until the complete elimination of the axial forces.

To reduce the cost of manufacture of the body, the shape-generating insert of the press form is made recoverable. This allows changing the internal geometry of the body depending on the intended mode of operation of the pump.

It should be noted that the increase in the degree of control of a centrifugal pump can be achieved through dynamic modification of transmission as well, namely, the regulation of revolutions transmitted from the engine to the impeller in a mechanical way, with the help of fluid coupling and frequency converters.

\section{Conclusions}

1. A centrifugal pump as a technical system consists of the following major structural subsystems: the impeller blades, the discs of the impeller, the body, the discharge nozzle, and the suction nozzle.

2. The general trend for the development of all subsystems of the centrifugal pump is to increase the degree of their controllability, in particular, due to the dynamic modification replacement of rigid elements for more flexible ones.

3. The more important the function of a subsystem, the more it affects the main useful function of the pump, the more technical solutions aimed to manage this subsystem. Therefore, the greatest number of changes is at the expense of the working body of the impeller blades. 4. Further increase controllability, and hence the main useful function of the pump may occur due to the use of "smart" compounds and materials with predetermined properties, for example, alloys with shape memory.

5. Using a rational algorithm for the dynamic modification of technical systems, one can predict the further trajectory of the development of the centrifugal pump.

\section{References}

1. V. E. Afanasyev, I. M. Kondrakov V. I. Zhadanov, Use of materials with thermomechanical shape memory for solution of the applied problems in construction engineering complex. Journal of Siberian Federal University. Series: Engineering and technology, 4, 529-535 (2016)

2. I. M. Kondrakov, Learn the laws of the world. Saint Petersburg, RNTO (In Russian) (2015)

3. I. M. Kondrakov, Rational algorithm of technical systems dinamization. Vestnik BelGTASM, Materialy mezhdunarodnoy konferenzhii "Sovremennye technologii v promyshlennosti stroitelnych materialov i stroiindustrii, 5, 367-371 (In Russian) (Belgorod, 2003)

4. O. G. Dubrovskaya, Technology of hydrothermodinamic treatment of natural and sewage water with the use of cavitation effects. Cand. Diss. (Krasnoyarsk, 2007)

5. O. G. Dubrovskaya, V. A. Kulagin Features of supercavitation evaporators. Vestnik assotshiatshii vypusknikov Krasnoyarskogo gosudarstvennogo universiteta. 13, 168179 (2006)

6. R. F. Patent, 98500. Tsentrobezhnyi nasos [Centrifugal pump] (In Russian) (2010) 